\title{
Perencanaan Rekonfigurasi Jaringan Tegangan Menengah Pada Kampus Universitas Udayana Bukit Jimbaran
}

\author{
I Putu Andithya Chrisna Budi ${ }^{1}$, I. A. Dwi Giriantari ${ }^{2}$, I Wayan Sukerayasa ${ }^{3}$
}

\begin{abstract}
Reconfiguration of the medium-voltage network in Bukit Jimbaran Udayana University campus aims to obtain a reliable electricity system. The study shows that before the interconnection of Kedonganan Feeder with generator set and PLTS in campus, the power loss is $115,5 \mathrm{~kW}$. After using generator set, the power loss was reduced into $86,6 \mathrm{~kW}$ and with interconnection of generator sets and PLTS, the power loss was reduced into 86,5 $\mathrm{kW}$. the reliability of Kedonganan Feeder also improved with SAIFI index = 0,8298 interference / customer. year, or disruptions in a year is less than once/ customer, SAIDI $=2,9006$ hours $/$ customer.year, or the duration of outage in a year is about 3 hours per customer, CAIDI $=3,495$ hours $/$ disruption or the duration of outage is 3 hours 30 minutes per outage. In the analysis of emergency conditions (when PLN off), it can be seen that, the power plant owned by Bukit Jimbaran Udayana University campus is overload in FT generator, rectorate generator set, and PLTS FT.
\end{abstract}

Intisari- Jaringan tenaga listrik yang mensuplai Universitas Udayana merupakan bagian dari Penyulang Kedonganan. Rekonfigurasi jaringan distribusi tenaga listrik kampus Universitas Udayana Bukit Jimbaran bertujuan untuk meningkatkan performa jaringan suatu sistem kelistrikan yang handal . Dari studi yang sudah dilakukan di dapatkan hasil $115,5 \mathrm{~kW}$ dari rugi daya pada Jaringan Distribusi Penyulang Kedonganan sebelum terpasangnya pembangkit generator set dan PLTS yang terdapat pada kampus. Setelah terpasangnya Pembangkit generator set terjadi penurunan rugi daya sebesar $86,6 \mathrm{~kW}$ dan setelah terpasangnya generator set dan PLTS rugi dayanya sebesar $86,5 \mathrm{~kW}$ dari total rugi daya yang terjadi sebelum interkoneksi pembangkit generator set dan PLTS. Serta meningkatnya keandalan Penyulang Kedonganan dengan indeks SAIFI $=0,8298$ gangguan/pelanggan.tahun atau terjadinya gangguan dalam setahun kurang dari $1 \mathrm{kali} /$ pelanggan, SAIDI = 2,9006 jam/pelanggan.tahun atau durasi pemadaman dalam setahun sekitar 3 jam per pelanggan, CAIDI $=3,495$ jam/ganguan atau lama durasi pemadaman dalam satu kali pemadaman selama 3 jam 30 menit. Pada analisis kondisi emergency (saat PLN padam) dapat diketahui bahwa, terdapat overload pada generator set FT, generator set Rektorat dan PLTS FT.

Kata Kunci- Rekonfigurasi, Rugi Daya, Keandalan, Emergency

\section{PENDAHULUAN}

Universitas Udayana adalah perguruan tinggi negeri di Bali, kampus ini terdapat banyak gedung-gedung yang dipakai untuk perkuliahan, laboratorium, rumah sakit, dan kantor

\footnotetext{
${ }^{1}$ Mahasiswa, Jurusan Teknik Elektro dan Komputer Fakultas Teknik Universitas Udayana, e-mail: bunches.xxx2@gmail.com

${ }^{2}$ Dosen, Jurusan Teknik Elektro dan Komputer Fakultas Teknik Universitas Udayana, e-mail:dayu.giriantari@yahoo.com

${ }^{3}$ Dosen, Jurusan Teknik Elektro dan Komputer Fakultas Teknik Universitas Udayana,

e-mail: sukerayasawayan@unud.ac.id
}

rektorat. Kebutuhan energi listrik Universitas Udayana disuplai oleh trafo utama Gardu Induk (GI) Nusa Dua. Di kampus Universitas Udayana Bukit Jimbaran ada beberapa gedung yang sangat penting diantaranya adalah gedung Rektorat dan Rumah Sakit Udayana yang harus stand by atau siaga setiap waktu jika ada pemadaman listrik. Maka dari itu untuk menjamin suplai energi listrik di kampus disiapkan beberapa generator set sebagai backup suplai jika ada pemadaman dari PLN. Tetapi sistem backup dengan menggunakan generator set saat ini masih di desain secara partial sehingga tidak menjamin keandalan suplai kampus. Dengan melakukan rekonfigurasi untuk memperoleh sistem kelistrikan yang lebih handal diharapkan bisa meningkatkan pelayanan kelistrikan di area kampus Universitas Udayana Bukit Jimbaran dan dapat meningkatkan kenyamanan bagi kampus dalam perkuliahan.

Studi dilakukan dengan cara mengumpulkan data-data yaitu : mencari diagram single line Penyulang Kedonganan, data transformator, penggunaan beban transformator, panjang saluran penghantar dan jenis penghantar, laju kegagalan, waktu perbaikan semua komponen, mendesain penempatan switch dan penempatan pembangkit. Adapun analisis dari studi ini dibantu dengan software.

\section{REKONVIGURASI JARINGAN}

Network Reconfiguration adalah suatu usaha mengubah bentuk konfigurasi jaringan distribusi dengan mengoperasikan pensakelaran terkontrol jarak jauh pada jaringan distribusi tanpa menimbulkan akibat yang beresiko pada operasi dan bentuk sistem jaringan distribusi secara keseluruhan. Rekonfigurasi jaringan dilakukan agar dapat menurunkan rugi daya pada sistem dan meningkatkan keandalan pada sistem [1].

\section{A. Indeks Keandalan}

Indeks keandalan biasanya dievaluasi dengan cara menghitung failure rate $(\lambda)$, waktu perbaikan(r), dan Unavailability (U) [2].

a. SAIFI (System Average Interruption Frequency Index). Merupakan ukuran jumlah rata-rata dari gangguan yang terjadi dalam satu tahun dan ditetapkan ke dalam bentuk persamaan [2] :

$$
S A I F I=\frac{\sum \lambda_{i} \cdot N_{i}}{\sum N_{i}}
$$

b. SAIDI (System Average Interruption Duration Index Merupakan waktu kegagalan rata-rata dalam satu tahun untuk tiap pelanggan dan ditetapkan ke dalam bentuk persamaan [2] :

$$
S A I D I=\frac{\sum U_{i} \cdot N_{i}}{\sum N_{i}}
$$

c. CAIDI (Customer Average Interruption Duration Index). Merupakan lama rata-rata dari sebuah gangguan yang pernah 
dialami oleh pelanggan dan ditetapkan ke dalam bentuk persamaan :

$$
C A I D I=\frac{\sum U_{i} \cdot N_{i}}{\sum \lambda_{i} N_{i}}
$$

\section{HASIL DAN PEMBAHASAN}

\section{A. Analisis Rugi Daya Penyulang Kedonganan}

Analisis rugi daya dilakukan dengan bantuan software. Dalam analisis ini diperlukan data seperti data transformator, data beban transformator, data panjang saluran penghantar, dan jenis penghantar.

Perhitungan Rugi daya pada software menggunakan data existing pada sistem distribusi $20 \mathrm{KV}$ penyulang Kedonganan. Dengan simulasi tiga kondisi. Titik kondisi pertama adalah pada saat kondisi penyulang Kedonganan tanpa generator set dan PLTS, kondisi kedua pada saat terinterkoneksi dengan generator set, dan kondisi ketiga pada saat terinterkoneksi dengan generator set dan PLTS yang lokasinya diasumsikan terpusat untuk mengurangi rugi daya pada Penyulang Kedonganan.

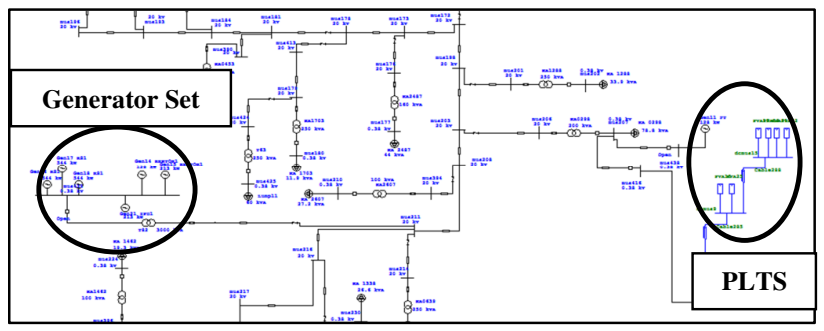

Gambar 1 Lokasi Interkoneksi Generator Set dan PLTS pada Penyulang Kedonganan

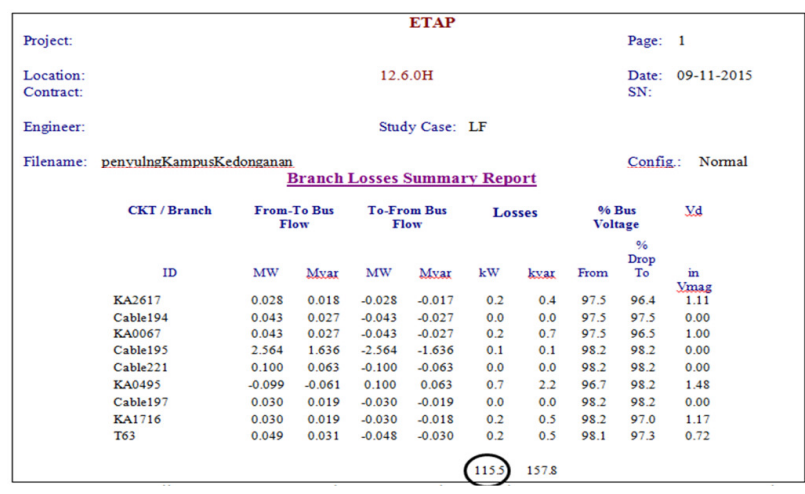

Gambar 2 Hasil Running software Rugi Daya Penyulang Kedonganan Tanpa Generator Set dan PLTS

Dari gambar 2 dapat dilihat hasil running dari software untuk rugi daya Penyulang Kedonganan tanpa interkoneksi genset dan PLTS sebesar 115,5 kW.

Dari gambar 3 didapatkan hasil running software rugi daya Penyulang Kedonganan dengan generator set sebesar $86,8 \mathrm{~kW}$.

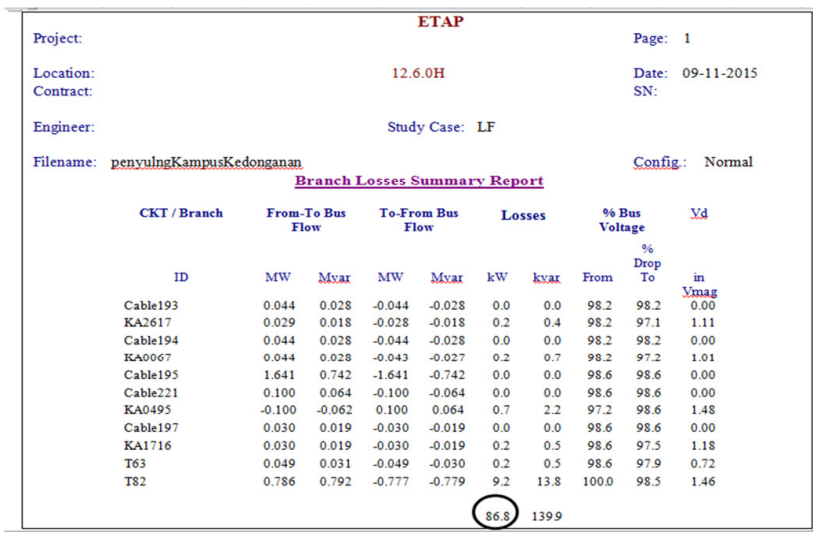

Gambar 3 Hasil Running software Rugi Daya Penyulang Kedonganan dengan Generator Set

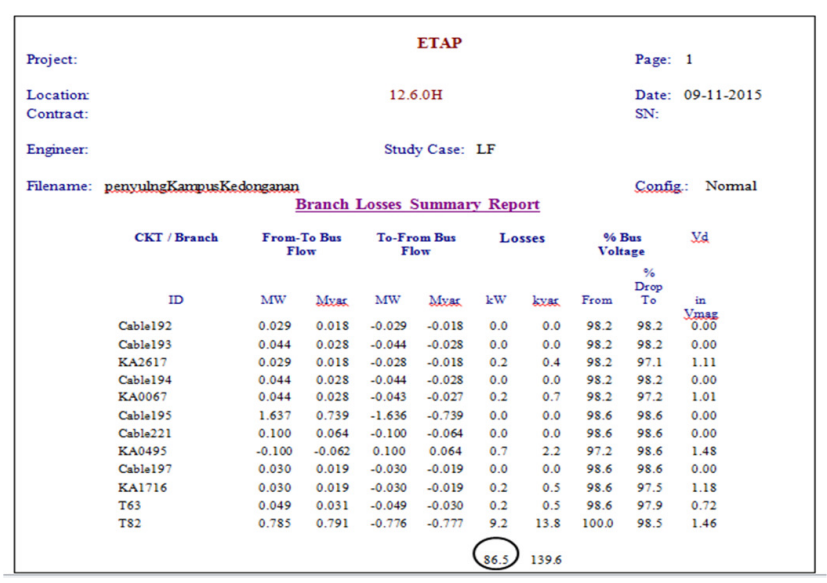

Gambar 4 Hasil Running software Rugi Daya Penyulang Kedonganan dengan Generator dan PLTS

Dari gambar 4 hasil running software rugi daya Penyulang Kedonganan dengan interkoneksi genset dan PLTS sebesar $86,5 \mathrm{~kW}$. berikut adalah tabel perbandingan nilai rugi daya sebelum dan sesudah terinterkoneksi pembangkit.

TABEL I

PERBANDINGAN NILAI RUGI DAYA SEBELUM DAN SESUDAH MASUKNYA PEMBANGKIT

\begin{tabular}{|c|c|c|}
\hline $\begin{array}{c}\text { TANPA } \\
\text { PEMBANGKIT } \\
\text { (KW) }\end{array}$ & $\begin{array}{c}\text { GENERATOR } \\
\text { SET } \\
(\text { KW) }\end{array}$ & $\begin{array}{c}\text { GENERATOR SET } \\
\text { DAN PLTS } \\
(\text { KW) }\end{array}$ \\
\hline 115,5 & 86,8 & 86,5 \\
\hline
\end{tabular}

Dari tabel I dapat diketahui bahwa pada Penyulang Kedonganan penurunan rugi daya mencapai $24,8 \%$ dengan tambahan generator set dan penurunan rugi daya sebesar $25,1 \%$ dengan tambahan generator set serta PLTS d

Berikut ini adalah gambar pada saat pembangkit di letakkan secara terpisah, atau dalam hal ini pada kondisi exisiting yang ditunjukan pada gambar 5.

I Putu Andithya Chrisna Budi: Perencanaa Rekonfigurasi Jaringan Tegangan... $\quad$ p-ISSN:1693 - 2951; e-ISSN: $2503-2372$ 


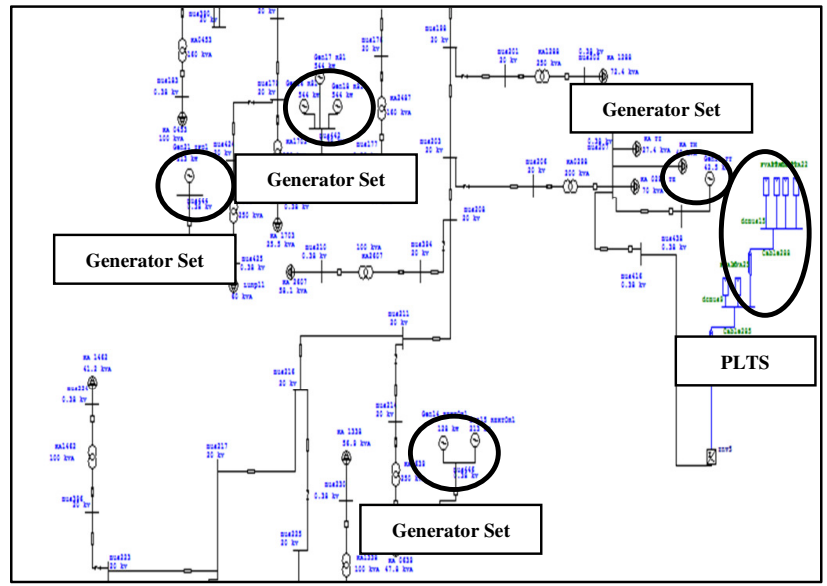

Gambar 5 Lokasi Generator Set dan PLTS pada kondisi existing

Pada gambar 5 didapatkan hasil rugi daya sebesar 101,2 kW Setelah terinterkoneksi oleh generator set dan PLTS hasil running tersebut lebih besar dibandingkan dengan desain peletakan pembangkit yang terpusat yaitu sebesar $86,5 \mathrm{~kW}$.

B. Analisis Tingkat Keandalan Pada Penyulang Kedonganan

Analisis tingkat keandalan pada Penyulang Kedonganan menggunakan parameter-parameter yang diperlukan dalam software seperti :

1. Data transformator

2. Beban setiap transformator

3. Jenis penghantar

4. Panjang saluran

5. Laju kegagalan

6. Waktu perbaikan dari semua komponen-komponen.

Hasil dari simulasi tingkat keandalan pada Penyulang Kedonganan dapat dilihat pada tabel 2.

TABEL II

NILAI INDEKS KEANDALAN PENYULANG KEDONGANAN

\begin{tabular}{|c|c|c|c|}
\hline Indeks Keandalan & $\begin{array}{c}\text { Tanpa } \\
\text { Pembangkit }\end{array}$ & $\begin{array}{c}\text { Generator } \\
\text { Set }\end{array}$ & $\begin{array}{c}\text { Generator } \\
\text { Set dan } \\
\text { PLTS }\end{array}$ \\
\hline $\begin{array}{c}\text { SAIFI (Gangguan/ } \\
\text { Pelanggan.Tahun) }\end{array}$ & 3,0195 & 0,8296 & 0,8298 \\
\hline SAIDI(Jam/Pelanggan.Tahun) & 13,3899 & 2,8987 & 2,9006 \\
\hline CAIDI (jam/Gangguan) & 4,434 & 3,494 & 3,495 \\
\hline
\end{tabular}

Dari tabel II dapat diketahui bahwa terjadi peningkatan nilai keandalan pada Penyulang Kedonganan setelah interkoneksi generator set dan PLTS yang dapat dilihat dari turunnya nilai SAIFI dan SAIDI. Grafik perbandingan indeks keandalan Penyulang Kedonganan dengan kondisi tanpa interkoneksi pembangkit dan terinterkoneksi pembangkit dapat dilihat pada gambar 6 .

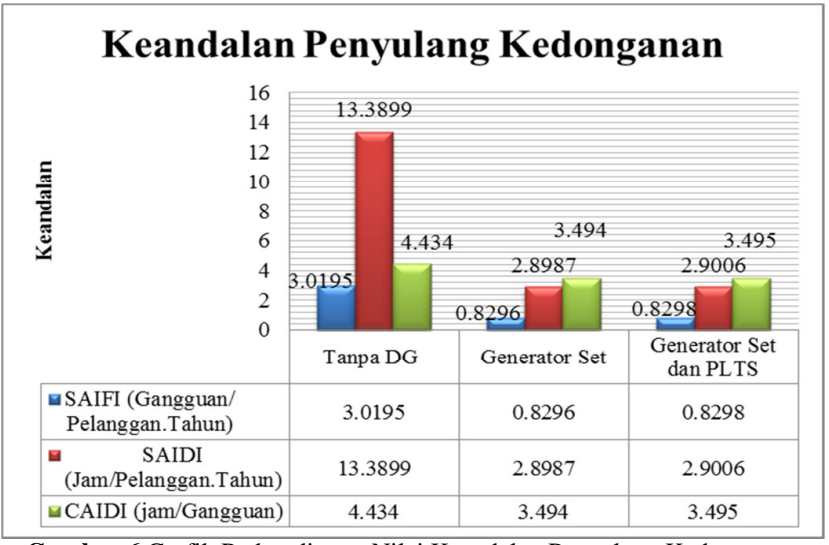

Gambar 6 Grafik Perbandingan Nilai Keandalan Penyulang Kedonganan Tanpa Pembangkit dan Interkoneksi Pembangkit Generator Set dan PLTS

Dari grafik tersebut kondisi Penyulang Kedonganan dengan interkoneksi generator set dan PLTS memiliki tingkat keandalan yang lebih tinggi dibandingkan dengan kondisi Penyulang Kedonganan tanpa interkoneksi pembangkit.

\section{Analisis Kondisi Emergency Pada Saat PLN Padam}

Pada saat PLN padam diharapkan Pembangkit yang terdapat pada Kampus Universitas Udayana Bukit Jimbaran dapat menyuplai ke seluruh beban kampus Udayana Bukit Jimbaran. untuk itu sistem kapus harus dapat diisolasi dari jaringan lain dengan menempatkan switch, penempatan switch pertama diletakkan pada jaringan distribusi $20 \mathrm{kV}$ di bagian Nirmala (lokasi antara trafo KA0618 dan trafo KA2487) sedangkan switch kedua diletakkan di bagian MIPA (lokasi antara trafo KA2577 dan trafo KA1338). Berikut adalah desain penempatan switch yang telah dibuat pada software
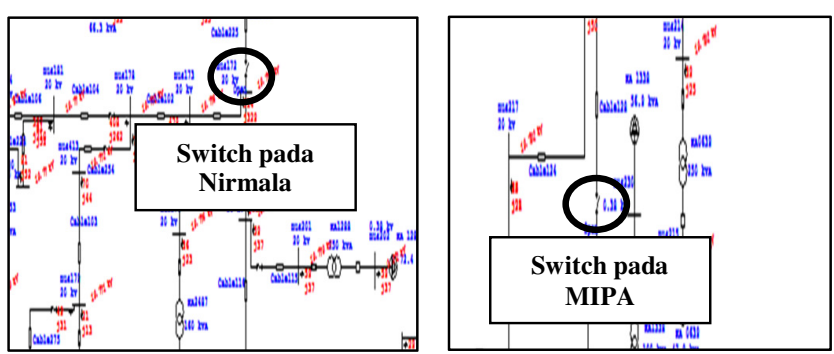

Gambar 7 Penempatan Switch

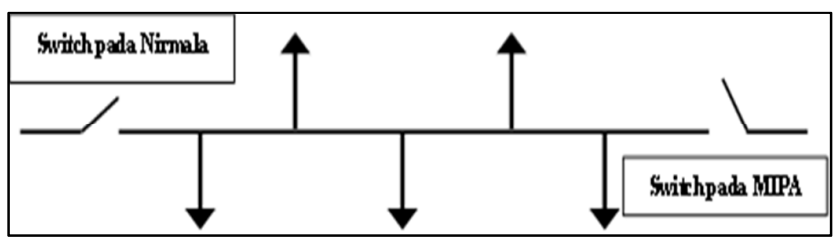

Gambar 8 Desain penempatan Switch 


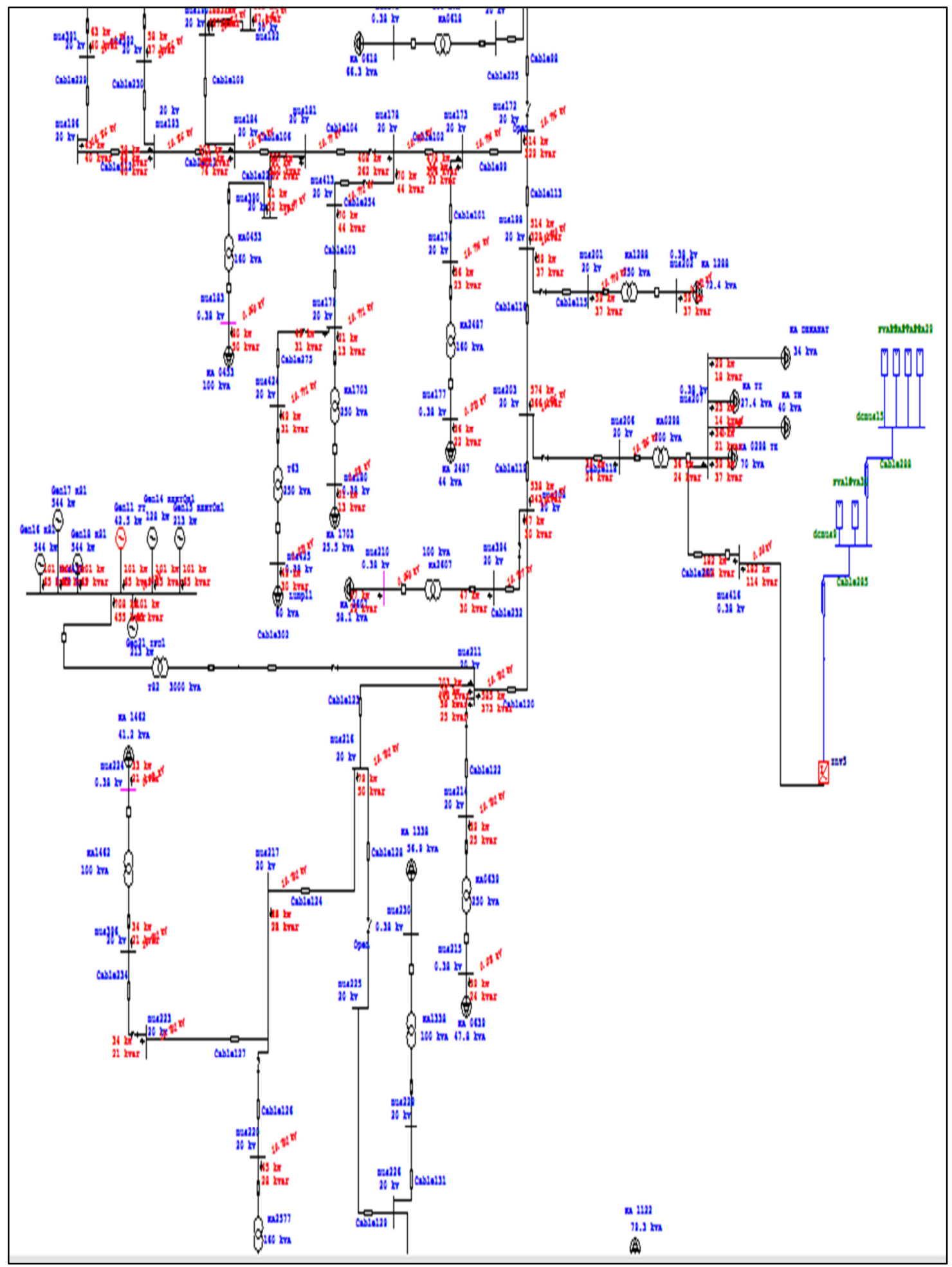

Gambar 9 Simulasi Emergency Pada saat PLN Padam

I Putu Andithya Chrisna Budi: Perencanaa Rekonfigurasi Jaringan Tegangan...

p-ISSN:1693 - 2951; e-ISSN: 2503-2372 
Gambar 9 merupakan simulasi yang telah dibuat pada software pada saat kondisi PLN padam switch yang telah di desain dan di pasang pada jaringan distribusi $20 \mathrm{kV}$ terbuka dan membuat pembangkit yang terdapat pada area kampus menyuplai beban-beban di lingkungan kampus saja.

Berdasarkan hasil simulasi yang telah dibuat dapat diketahui bahwa, pada saat PLN padam pembangkit yang terdapat pada kampus Universitas Udayana Bukit Jimbaran mengalami overload yang terjadi di GenFT, PLTS FT, dan Gen Rektorat. Terjadinya overload karena pada pendesainan data yang dimasukkan masih terdapat data pelanggan lain selain Universitas Udayana, sehingga agar tidak adanya overload pada pembangkit, perlu adanya pemisahan bebanbeban selain beban Universitas Udayana. Selain itu pada saat PLN padam pembangkit yang ada agar dapat menyuplai beban kampus yang dianggap penting seperti Gedung Rektorat, Rumah Sakit Udayana, Laboratorium yang terdapat di Universitas Udayana. Selain itu pula kapasitas generator set dan PLTS yang terdapat di area kampus di tambah.

\section{KESIMPULAN}

Berdasarkan hasil penelitian ini, maka dapat diambil kesimpulan sebagai berikut.

1. Dari hasil data yang diperoleh kapasitas pembangkit yang ada di area kampus Universitas Udayana Bukit Jimbaran adalah terdapat 7 buah generator set dan 6 array PLTS yang masing-masing memiliki kapasitas tertentu diantaranya adalah 3 buah genset pada Rumah Sakit
UNUD sebesar $2040 \mathrm{kVA}$, 2bh genset gedung rektorat sebesar $150 \mathrm{kVA}$ dan $250 \mathrm{kVA}$, 1bh genset gedung IPD sebesar 250 kVA, 1 bh genset Fakultas Teknik sebesar 50 kVA dan 48bh PLTS yang total berkapasitas 392,83 Watt.

2. Dari hasil analisis emergency pada saat PLN padam hasil simulasi yang telah dibuat dapat diketahui bahwa, pada saat PLN padam pembangkit yang terdapat pada kampus Universitas Udayana Bukit Jimbaran mengalami overload pada generator set (Gen FT, Gen Rektorat) dan PLTS FT.

\section{REFERENSI}

[1] Zimmerman, D. 1992. Network reconfiguration for loss reduction in three-phase power distribution sistems, http://stealth.ee.cornell.edu/ray/pubs/MSThesis.pdf., Diakses Juli 2015

[2] Billinton, A dan Ronald. 1996. Reliability Evaluation of Power Systems. 2nd ed. New York: Plenum Press.

[3] Xie K., Zhou J., dan Billinton R. 2008. "Fast algorithm for the reliability evaluation of large scale electrical distribution networks using the section technique", IET Gener. Transm. Distrib., Vol. 2, No.5, pp. 701-707, 2008.

[4] Wicaksono., Hernanda., Dan Penangsang. 2012. Analisis Keandalan Sistem Distribusi Di PT. PLN (Persero) APJ Kudus Menggunakan Software ETAP (Electrical Transient Analysis Progam) Dan Metode Section Technique. Paper. Surabaya. http://digilib.its.ac.id/public/ITSpaper-22204-2208100186-Paper.pdf. diakses Juni 2015.

[5] Sonixtus. 2008. Estimasi Rugi-rugi Energi Pada Sistem Distribusi Radial $20 \mathrm{kV}$ dengan Menggunakan Pendekatan Aliran Daya Pada Program ETAP Power Station 4.0.0 Studi Kasus : Sistem Distribusi Jawa Timur Penyulang GI Waru. Surabaya: Universitas Kristen Petra. 